\title{
An international survey of speciality training in oral and maxillofacial pathology
}

\author{
Keith Hunter ${ }^{1, *}$, Paul Speight ${ }^{2}$, John Wright ${ }^{3}$, Willie van Heerden ${ }^{4}$, Alison Rich $^{5}$ and \\ Christopher Franklin ${ }^{1}$
}

${ }^{1}$ Oral Pathology, University of Sheffield, Sheffield, UK;

${ }^{2}$ Department of Oral Pathology, School of Clinical Dentistry, Sheffield, UK;

${ }^{3}$ Department of Diagnostic Sciences, Texas A\&M Health Science Center Baylor College of Dentistry, Dallas, TX, USA;

${ }^{4}$,Department of

Oral Pathology and Oral Biology, University of Pretoria, Pretoria, South Africa;

${ }^{5}$ University of Otago, Dunedin, New Zealand

${ }^{*}$ Correspondence: Keith Hunter, Oral Pathology, School of Clinical Dentistry, University of Sheffield, Claremont Crescent, Sheffield, S10 2TA, UK. Tel: +44 (0)114 271 7956, Fax: +44 (0)114 2717894 ,

E-mail: k.hunter@sheffield.ac.uk

\section{Abstract \\ Background}

Speciality training in oral and maxillofacial pathology (OMFP) across the world would be aided by guidance on a generic curriculum and training programme that all countries could use as a template. In order to facilitate this, we require an understanding of the various forms which OMFP training takes across the world.

\section{Methods}

We sent a questionnaire to OMF pathologists in the 42 countries represented in the IAOP membership, via their Regional Councillor. The questionnaire included detailed demographics, entry requirements, specialty training program and facilities/resources.

\section{Results}

Replies were received from $22 / 42$ countries (52\%). OMFP is a dental/dental and medical speciality in $72 \%$, and in $92 \%$ of those, this is recognised by a licensing board. Training was undertaken in an academic environment in $85 \%$ (with many offering a further academic qualification) and the median length of training was 4 years. General/anatomical pathology training is mandated in $85 \%$ of programs and a common core of general sub-specialities was identified. An end of training assessment was conducted in $80 \%$ of programs with most including written, practical and oral elements. Training program directors and educational supervisors were in place in 12/16 programs and, in most, Quality Assurance of training was externally monitored. In only one country was the number of trainees linked to workforce planning.

\section{Conclusions}

Training in OMFP varies across the world. However, we feel there is sufficient commonality for the development of an agreed indicative framework on education and training in Oral and Maxillofacial Pathology, perhaps under the auspices of the IAOP.

Keywords: international survey; oral pathology; speciality training 


\section{Introduction}

Provision of speciality training in oral and maxillofacial pathology (OMFP) across the world would be aided by guidance on a generic curriculum and training program that all countries could adopt to support their needs. This is important if the speciality of OMFP is to grow and develop. A number of trans-national curricula/recommendations for pathology training, in various sub-specialities, at national and international level, exist (for example, Bolon et al 2011 (1)). Much of the impetus for this has come from globalisation and freedom of movement for employment, for example within the European Union, with a need to establish training equivalence and standardization of expertise. However, a recent survey of anatomical pathology training requirements in EU member states showed that the duration of training and requirements varied markedly and also indicated that, despite in excess of 20 years work towards pan-European standardisation, little substantive progress has been made (2). Nevertheless, a European Pathology Training Curriculum does exist (EUROPALS (3)): the extent of agreement with and implementation of this is not known. It must also be remembered that the practice of Oral Pathology solely with a dental qualification is not legal in many countries.

Table 1. Countries with agreed and published national standards for OMFP training with web links

\begin{tabular}{|l|l|l|}
\hline Country & Organisation & Weblink \\
\hline $\begin{array}{l}\text { Australia } \\
\text { (5) }\end{array}$ & $\begin{array}{l}\text { The Royal College of } \\
\text { Pathologists of Australi }\end{array}$ & www.rcpa.edu.au/Careers/Training/CurriculumTrainingHandbook.htm \\
\hline $\begin{array}{l}\text { South } \\
\text { Africa } \\
(7)\end{array}$ & $\begin{array}{l}\text { The Colleges of medicin } \\
\text { of South Africa }\end{array}$ & www.collegemedsa.ac.za/view_exam.aspx?examid=37 \\
\hline $\begin{array}{l}\text { United } \\
\text { Kingdom } \\
\text { (4) }\end{array}$ & $\begin{array}{l}\text { General Dental } \\
\text { Council }\end{array}$ & $\begin{array}{l}\text { http://www.gdc- } \\
\text { uk.org/Dentalprofessionals/Specialistlist/Documents/OMPCurriculum.pdf }\end{array}$ \\
\hline $\begin{array}{l}\text { United } \\
\text { States (6) }\end{array}$ & $\begin{array}{l}\text { American Dental } \\
\text { Association } \\
\text { See also: American Boa } \\
\text { of Oral } \\
\text { and Maxillofacial } \\
\text { Pathology }\end{array}$ & $\underline{\text { www.ada.org/sections/educationAndCareers/pdfs/omp.pdf }}$ \\
\end{tabular}

Accepted standards and curricula for training in oral and maxillofacial pathology are even less common. A few do exist (Table 1), for example, in the United Kingdom, a national curriculum was approved by the General Dental Council and the Royal College of Pathologists. (4) A curriculum is also available in Australia (5). In the USA, advanced education programs must be accredited by the American Dental Association's Commission on Dental Accreditation which allows program flexibility while prescribing the minimal acceptable curricular requirements (6). At the International Association of Oral Pathologists (IAOP) Congress in Brisbane, Australia in 2006, there was a session on education and training in Oral and Maxillofacial Pathology. From this discussion, the authors felt it would be worthwhile for the IAOP to take the lead in developing an internationally agreed framework or template which could be used by member countries to help establish, promote or monitor OMFP training. Furthermore, it might be useful for countries developing the specialty, if there was an internationally agreed framework that could be referred to. In order 
to facilitate our understanding of how training in OMFP is organised around the world, we devised a survey/questionnaire to obtain information from other countries.

\section{Materials and Methods}

Each of the 257 countries of the world was placed into a regional group; Europe, North America, South and Central America, Africa, Asia and Australasia. Within each of these groups, the number of countries was narrowed down to the countries represented in the IAOP membership, a total of 42 countries. We sent a survey questionnaire to senior pathologists/head of departments in these countries, via their IAOP Regional Councillor. Questionnaires were also made available to all delegates at the IAOP Congresses in 2008 (San Francisco, USA) and 2010 (Seoul, South Korea). The questionnaire included details of country demographics and the current status of the speciality, entry requirements for training, details of the specialty training program and facilities/resources (see supplementary document S1). Where returns were received from more than one source within a given country, the answers were collated into one response for the country. The compiled response was rechecked by the submitting pathologists before being subjected to further analysis.

On assessment of the level of completion of the surveys, responses were acceptable for analysis if a minimum of $80 \%$ of elements in a particular questionnaire were completed.

\section{Results}

\section{OMFP across the world}

Questionnaires were returned from 22 countries (52\%), shown in Figure 1. There was a median of 0.48 oral \& maxillofacial pathologists per million of population in a given country. OMFP was a recognised speciality in $16(72 \%)$ of the countries who responded. In $92 \%$ of countries where OMFP was a recognised speciality, it was recognised by a national licensing board or equivalent body. The median number of trainees per country was 4 (range 0-459). The number of trainees was regulated with respect to workforce planning in only one country (UK). This process matches the number of trainees to the need for specialists, taking into account projected retirements, at a national level. 


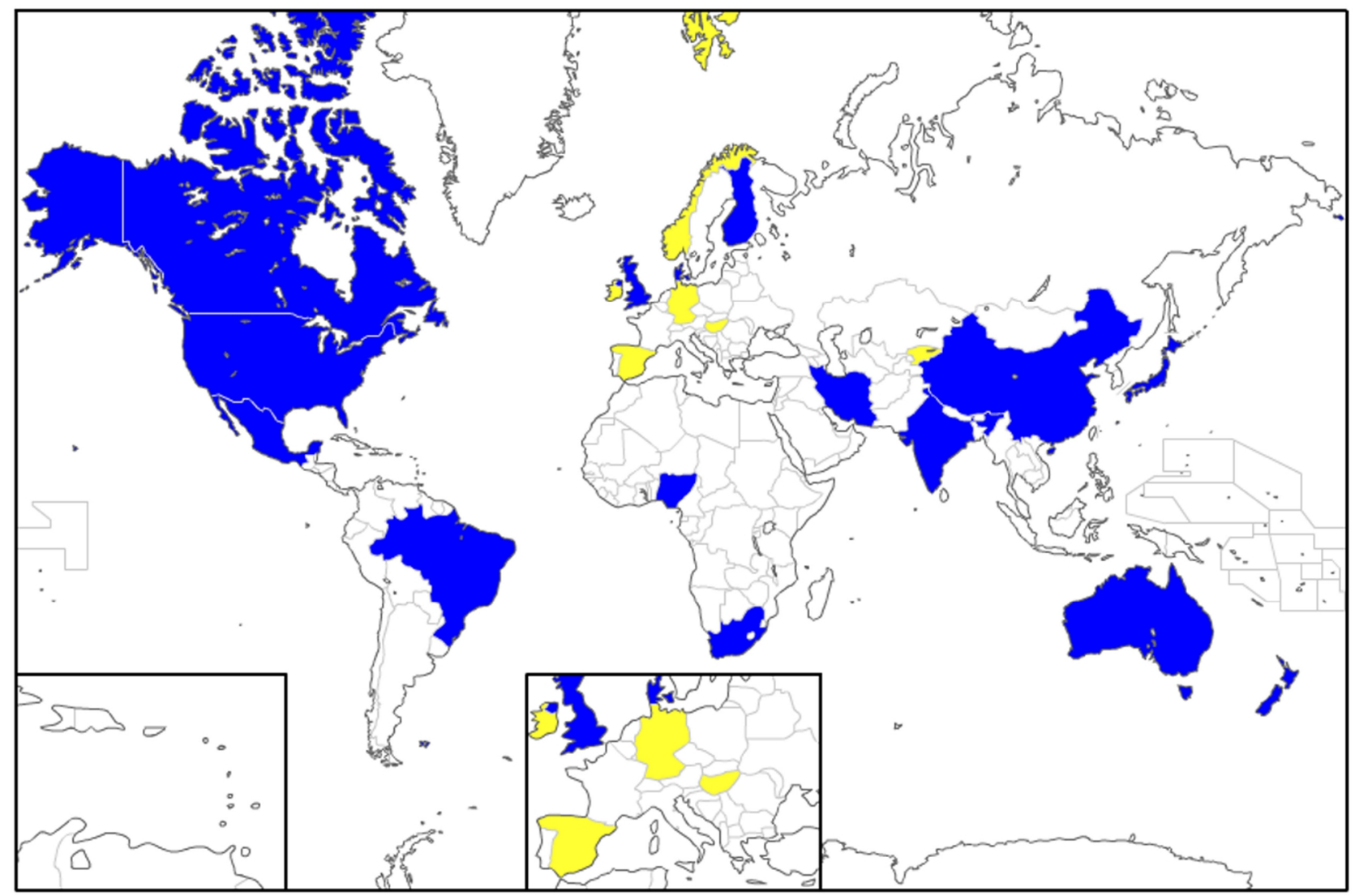

Figure 1. The world maps shows respondents from countries where OMFP is a dental speciality (blue) and those where it is a medical speciality, or neither (yellow). The figure was constructed using the online tool at http://edit.freemap.jp/en/trial version/edit/world.

\section{Entry to training}

The basic qualifications for entry to training were variable and largely depended on the speciality status of the speciality in a particular country. Basic qualifications for entry to training are shown in Figure 2. In the majority of programs, entry was open to dentally qualified trainees only (16 of $22 ; 72 \%$ ), as OMFP is regarded as a dental speciality. The methods used for selection of trainees were also variable. Five programs used examination as part of the selection process, however, most used application and/or interview $(47 \%$; Figure 2). 


\section{Entry requirements}

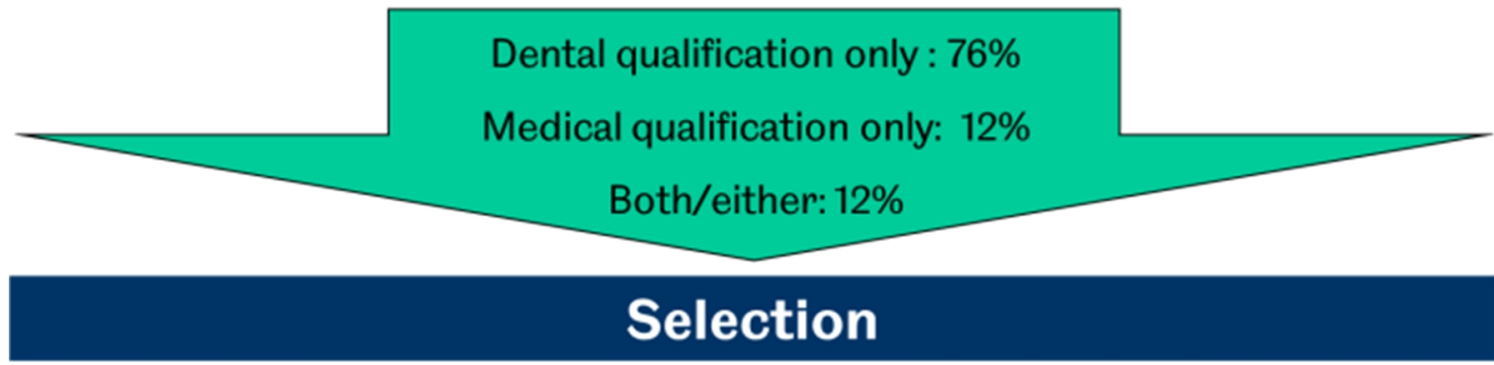

Examination: $29 \%$

Application/interview : $47 \%$

\section{Training period}

\section{Median length of training 4 years (Range 1-6 years)}

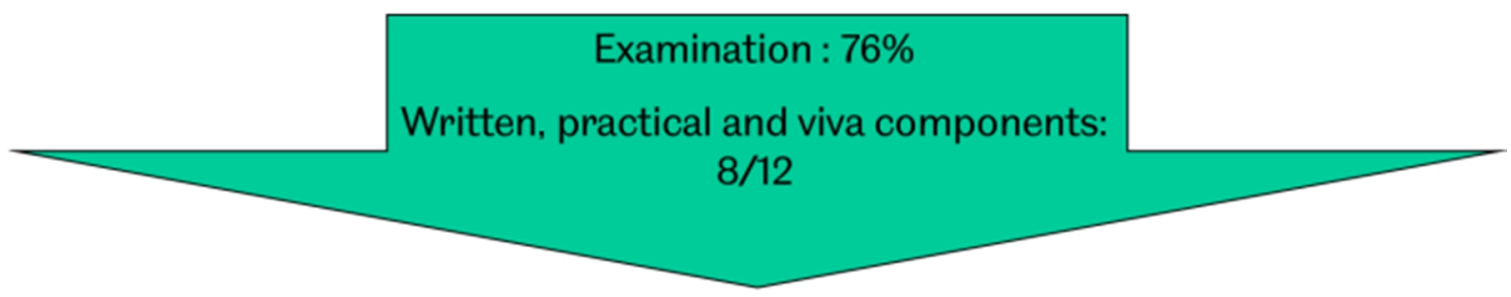

\section{Certification and registration}

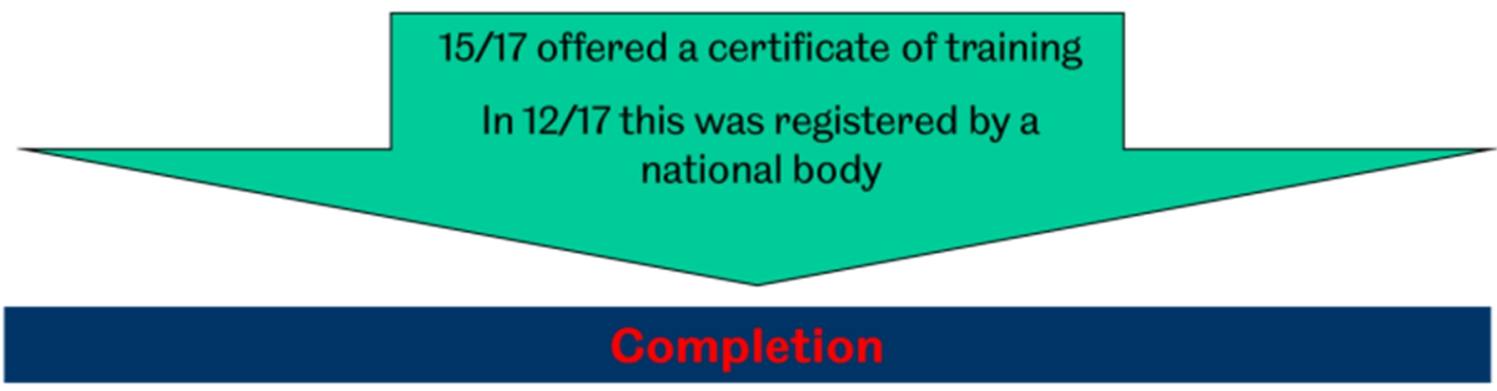

Figure 2. A flow diagram of the various common stages of training in OMFP across the world. The training period

The median length of speciality training was 4 years (range 1-6 years). Flexible or part-time training was offered in the training program of $37 \%$ of countries programs. In 9 programs, the trainee was paid a salary, but the salary level was very variable and not readily comparable between countries. Most training (in $81 \%$ of countries) was sited in a primarily academic environment. In the programs in 13 countries, a Masters level qualification was the highest qualification offered (8) or mandated (5), whilst in a further 5 , a PhD was the highest degree offered (This was only mandated in one program; Figure 3 ). However, it must be noted that in 3 countries the qualification required for accreditation in the specialty 
was a diploma or fellowship of an accrediting body, for example the Royal Colleges of Pathology in the UK and Australia or the Board of the American Academy of Oral \& Maxillofacial Pathology in USA, and that a higher research degree, whilst possible in these countries, played no formal part in the training and accreditation process.

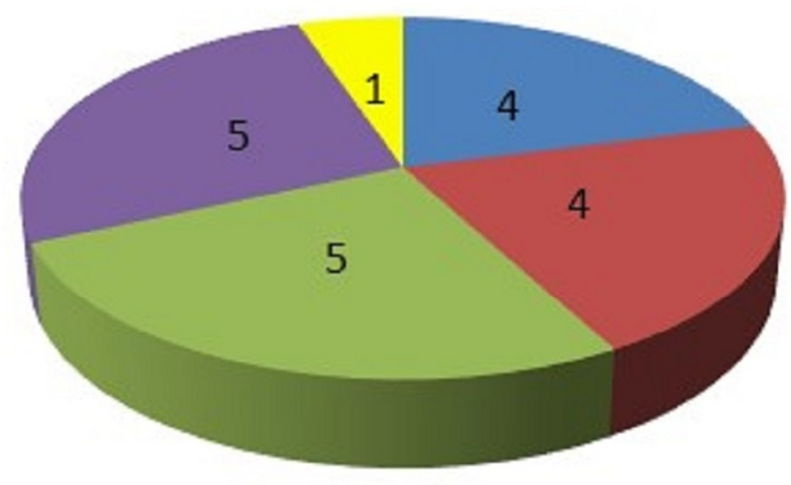

- No academic qualification offered

Masters degree offered

Masters degree mandated

$\mathrm{PhD}$ offered

PhD mandated

Figure 3. Further academic qualifications offered by the various programs, shown by the highest qualification offered/mandated. Note: In some where a PhD was offered, a Masters program was also offered.

All respondents indicated their trainees had access to both daily accessioned cases and to archived cases. There were varying exposures to molecular pathology $(68 \%)$ and rotations to other centres (47\%). Experience in forensic pathology/odontology was offered in $21 \%$, and $68 \%$ offered research experience as part of the training program. Seven programs conducted trainee appraisals at least once per year, with some conducting several per year. All of these programs offer support/remedial experience if a need is identified. General/anatomical pathology was a mandatory element to training in 14 programs, but in only 8 was this formally tested. Autopsy experience was included in 12 of these programs. Of 12 programs which responded in detail, 11 mandated GI, Endocrine, Skin, GU, ENT and lympho-reticular pathology experience, others were much more variable (Table 2). Some programs included microbiology and haematology. Patient contact as a component of training was very variable. Programs in nine countries offered some amount of patient contact and treatment, including interventional radiology (including sialography) and formal attachments to oral medicine.

\section{Accreditation and exit from training}

The programs in 13 countries had some form of formal end of training examination. In 8 of these the exam consisted of written, practical and viva/oral examination elements (Figure 2). Fifteen offered some form of certificate of training. In 12 there was a regulatory body which registered as part of specialist recognition.

\section{Quality assurance}

The quality of training was externally monitored in most programs. There was National level Quality Assurance with external review in $68 \%$ of programs. $75 \%$ of training programs had an overall training director and educational supervisor(s) to deliver the training on the 
ground. Training for the trainers was available in $68 \%$ of programs, and in most this was also quality assured/assessed.

\section{Discussion}

Following this survey, it is clear that there is marked variation in education and training but there are also many consistencies among countries. The skills required are largely the same, wherever OMFP is practised, but variation will come from a number of factors, including the status of the speciality (i.e. whether a dental speciality or a sub-speciality of medical pathology) in the country concerned and access to specialised or advanced techniques. Nevertheless, in most cases, as in anatomical pathology, the standard of training across the world in recognised programmes is generally high. A recent survey of postgraduate training in Oral Medicine showed very similar results. Whilst there was some variation in the content and length of training across the world, there was agreement in much of the syllabus of study (8).

To make progress towards some form of internationally agreed curriculum a number of issues need to be addressed; whilst there is a desire for an agreed curriculum, it is not clear if all interested parties agree on what that should look like in terms of level and extent of detail and method of assessment. Given the difficulties experienced in the development of a harmonised European pathology curriculum and associated assessment methods, it would be prudent not to fall into the trap of being overly prescriptive. This could have the effect of elimination of the locally focussed "apprenticeship" elements of pathology training in the name of standardisation. Flexibility in implementation will allow regional variation in needs to be taken into account, for example, with the geographic variability in infectious diseases and genetic diseases and their sequelae. Furthermore, the scope of Oral and Maxillofacial Pathology varies markedly across the world, with some training programs covering the full spectrum of Head and Neck Pathology, whilst others are much more limited to oral and dental pathology. There should be sufficient flexibility to allow individual countries to develop the speciality according to local needs. To ensure advances in the field of oral pathology trainees need experience in critical appraisal of the literature and current research/diagnostic methods, as well as being able to support their diagnostic decisions with current best evidence (9). However, the extent of any direct requirement for a research component within OMFP training needs to be debated.

Recommendations from the experience in Europe have now shifted from a detailed curriculum to agreed competencies at the end of training, with the development of common tools to measure these (2). Others have gone further, even questioning if it is a goal that we should be working toward at all (10). However, the lack of some form of training standard may inhibit global motility of the workforce and make cross-border accreditation very difficult.

Despite the variations identified in this survey, we feel it will be possible to develop an agreed framework on education and training in OMFP, perhaps based on the published curricula which are currently available (Table 2). This is ambitious, but through the initial development of working guidelines, an agreed framework of OMFP competences is 
Table 2. General pathology sub-specialities offered/mandated in OMFP training programs. This level of detail was recorded in 12 questionnaires.

\begin{tabular}{|l|c|}
\hline General Pathology "Core" & \% of programs \\
\hline Gastointestinal & 92 \\
\hline Endocrine & 92 \\
\hline ENT & 92 \\
\hline Lymphoreticular & 92 \\
\hline Genito-urinary/Gynae & 83 \\
\hline Bone and soft tissue & 75 \\
\hline Skin & 75 \\
\hline Others & \\
\hline Cytology & 65 \\
\hline Autopsy & 71 \\
\hline Microbiology & 65 \\
\hline Haematology & 65 \\
\hline Forensic pathology & 26 \\
\hline
\end{tabular}

achievable in the medium term. These will require to be developed by a working group, perhaps drawn from members of the IAOP, with support from various national OMFP bodies where these exist. This group would have the remit to develop, review and refer the framework following any feedback from members, with final ratification at a subsequent IAOP Annual General Meeting. A framework for monitoring implementation would then need to be put in place. This would be welcome to help further establish the speciality of OMFP and provide a basis for the development of OMFP in countries where it is not currently a recognised speciality.

\section{References}

1. Bolon B, Barale-Thomas E, Bradley A, Ettlin RA, Franchi CA, George C, Giusti AM, Hall R, Jacobsen M, Konishi Y, Ledieu D, Morton D, Park JH, Scudamore CL, Tsuda H, Vijayasarathi SK, Wijnands MV. International recommendations for training future toxicologic pathologists participating in regulatory-type, nonclinical toxicity studies. Exp Toxicol Pathol. 2011 Jan; 63(1-2):187-95.

2. Bosman FT, van den Tweel JG. Unison or cacophony: postgraduate training in pathology in Europe Virchows Arch. 2009 May; 454(5):497-503.

3. EUROPALS; http://www.eapcp.org/ Europals/training.htm

4. UK curriculum for training in Oral and Maxillofacial Pathology: http://www.gdcuk.org/Dentalprofessionals/Specialistlist/Documents/OMPCurriculum.pdf

5. Australian curriculum for training in Oral and Maxillofacial Pathology: http://www.rcpa.edu.au/Careers/Training/CurriculumTrainingHandbook.htm

6. The American Dental Association: (www.ada.org/sections/educationAndCareers/pdfs/omp.pdf).

7. The Colleges of medicine of South Africa: www.collegemedsa.ac.za/view exam.aspx?examid=37 
8. Rogers H, Sollecito TP, Felix DH, Yepes JF, Williams M, D'Ambrosio JA, Hodgson TA, Prescott-Clements L, Wray D, Kerr AR. An international survey in postgraduate training in Oral Medicine. Oral Dis. 2011 Apr; 17 Suppl 1:958.

9. Marchevsky AM. Evidence-based medicine in pathology: an introduction. Sem Diag Pathol. 2005 May; 22(2):105-115.

10. Taylor CR. Defining a global curriculum. Pathology International 2004; 54 (Suppl. 1): S103-S109 
International Survey of Training in Oral and Maxillofacial Pathology

K Hunter, CD Franklin, W van Heerden, A Rich, PM Speight and J Wright

\section{Section 1 - Demographics}

Country:

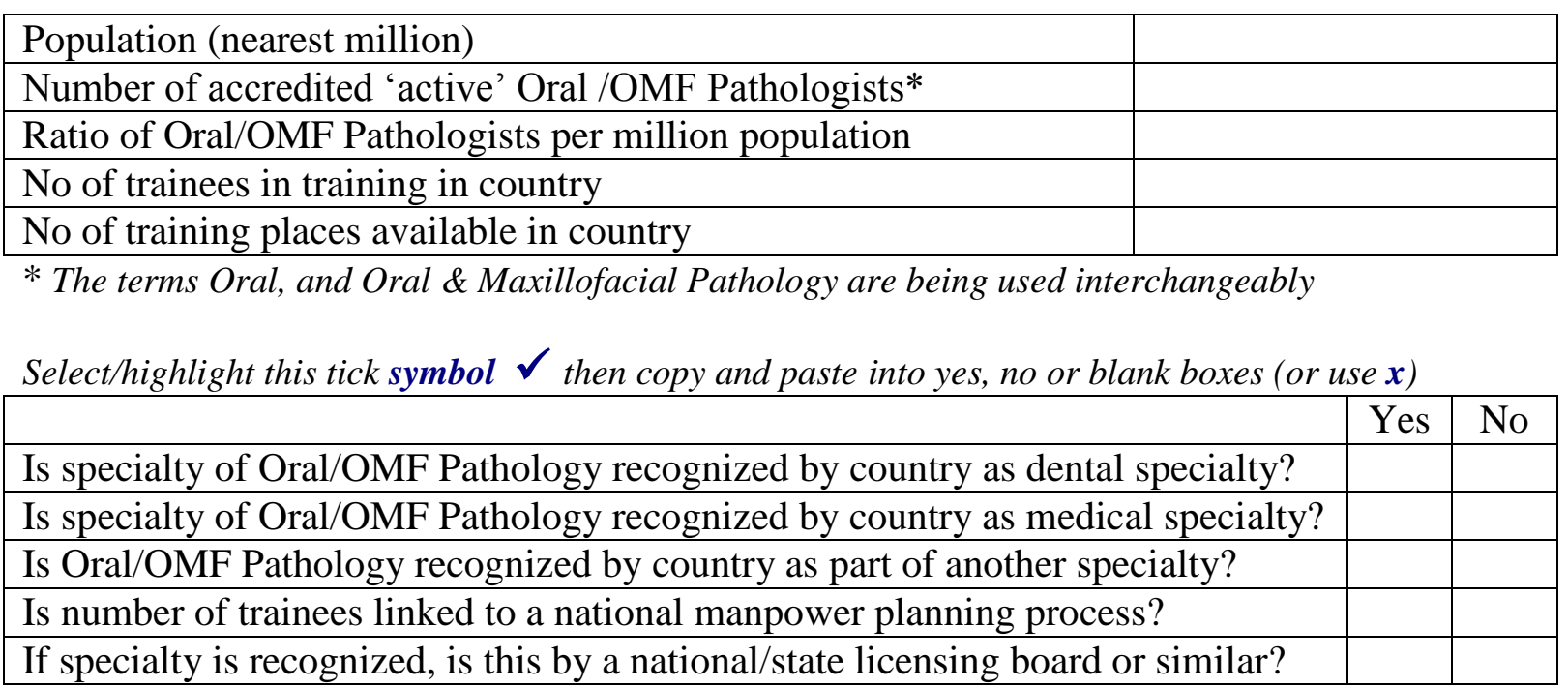

\section{Section 2 - Entry requirements}

Select/highlight this tick symbol $\checkmark$ then copy and paste into yes, no or blank boxes (or use $\boldsymbol{x}$ )

\begin{tabular}{|l|c|c|}
\hline & Yes & No \\
\hline Dentally qualified only? & & \\
\hline Medically qualified only? & & \\
\hline Medically and dentally qualified? & & \\
\hline
\end{tabular}

Period of postgraduate training/experience required before entry to specialty training

\begin{tabular}{|c|c|c|c|}
\hline 1 year & c & 2 years & \\
\hline
\end{tabular}

Briefly describe the selection process for entry into specialty training now or in near future (ie by interview, exam etc.).

\section{Section 3 - Specialty training}

Select/highlight this tick symbol $\checkmark$ then copy and paste into yes, no or blank boxes (or use $\boldsymbol{x}$ )

\begin{tabular}{|l|l|l|l|l|l|l|l|l|l|l|}
\hline \multicolumn{2}{|l|}{ Period of training in years } \\
\hline 1 & 2 & & 3 & & 4 & & 5 & & 6 or more & \\
\hline
\end{tabular}


Select/highlight this tick symbol $\checkmark$ then copy and paste into yes, no or blank boxes (or use $\boldsymbol{x}$ )

\begin{tabular}{|l|c|c|}
\hline Can program be certificate/license/membership only (ie without extra degrees)? & Yes & No \\
\hline Masters program mandatory & & \\
\hline Masters program optional & & \\
\hline PhD program mandatory & & \\
\hline PhD program optional & & \\
\hline
\end{tabular}

\begin{tabular}{|l|c|c|}
\hline & Yes & No \\
\hline Is training provided in academic setting only (ie dental/medical school/hospital) & & \\
\hline Is training provided in non-teaching hospital (ie not linked to med/dent school) & & \\
\hline
\end{tabular}

\begin{tabular}{|l|c|c|}
\hline & Yes & No \\
\hline Is training full time only? & & \\
\hline Is part time training possible? & & \\
\hline
\end{tabular}

If part time training is possible, what is the arrangement?

\begin{tabular}{|l|c|c|}
\hline & Yes & No \\
\hline Is the educational experience dictated by national accreditation standards & & \\
\hline Is accreditation/certification dependent on passing exam*/national/state boards & & \\
\hline
\end{tabular}

*Delete as appropriate

If yes which exam?

Certificate of completion of training provided?

\begin{tabular}{|l|l|}
\hline Yes & No \\
\hline & \\
\hline
\end{tabular}

Authority issuing certificate?

\begin{tabular}{|l|c|c|}
\hline & Yes & No \\
\hline $\begin{array}{l}\text { Does a regulatory body or similar health organisation, in your country, } \\
\text { recognize such a certificate? }\end{array}$ & & \\
\hline Is a period of anatomic (morbid)/general pathology training formally required? & & \\
\hline
\end{tabular}

If yes, how long is this period of training?

\begin{tabular}{|l|c|c|}
\hline & Yes & No \\
\hline Is general pathology competence tested? & & \\
\hline $\begin{array}{l}\text { Does the Oral/OMF Pathology training program have a competency framework } \\
\text { against which the trainee is assessed? }\end{array}$ & & \\
\hline Is autopsy experience required? & & \\
\hline If yes, is specific minimum number required? & & \\
\hline
\end{tabular}

Please indicate below

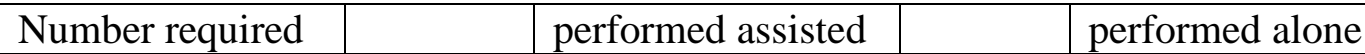


Areas of general pathology training that trainees are required* to undertake:-

\begin{tabular}{|c|c|c|c|}
\hline GI tract & Endocrine-Thyroid & Skin & Neuropathology \\
\hline GU & Larynx/Pharynx & Lymphoreticular & Pediatric \\
\hline Bone & Chemical Pathology & OBGYN & Other? \\
\hline Microbiology & Hematology & Virology & Cytology \\
\hline
\end{tabular}

Please indicate all that apply by * using $\boldsymbol{M}$ to indicate any that are Mandatory or $\boldsymbol{O}$ for those that are $\boldsymbol{O}$ ptional

\begin{tabular}{|l|c|c|}
\hline & Yes & No \\
\hline Do trainees have access to a set number of Oral/OMFP Cases per year? & & \\
\hline Do trainees use daily accessioned cases only for training? & & \\
\hline Do trainees use daily archived cases only for training? & & \\
\hline Do trainees use daily accessioned and archived/study sets* cases for training? & & \\
\hline
\end{tabular}

* Delete any not applicable

Select/highlight this tick symbol $\checkmark$ then copy and paste into yes, no or blank boxes (or use $\boldsymbol{x}$ )

\begin{tabular}{|l|l|l|}
\hline & Yes & No \\
\hline Is training provided in molecular pathology/genetics in relation to diagnosis? & & \\
\hline Is training provided in writing pathology reports? & & \\
\hline Is training provided in scientific writing? & & \\
\hline Is training provided in forensic dentistry? & & \\
\hline Are trainees expected to undertake a research module (not part of masters etc) & & \\
\hline Is clinical involvement (ie oral medicine/surgery) required as part of training? & & \\
\hline Are trainees expected to diagnose and manage clinical patients? & & \\
\hline $\begin{array}{l}\text { Are trainees expected to undertake training in imaging techniques ie } \\
\text { Radiography, CT or MRI }\end{array}$ & & \\
\hline If so, are they required to learn to do interventional techniques ie sialography? & & \\
\hline
\end{tabular}

If clinical involvement is required, briefly describe requirement

\begin{tabular}{|l|c|c|}
\hline & Yes & No \\
\hline Is mandatory $\mathrm{CPD} / \mathrm{CE}^{\dagger}$ required during training? & & \\
\hline Is $\mathrm{CPD} / \mathrm{CE}$ in addition to that required in training programme? & & \\
\hline
\end{tabular}

${ }^{\dagger} C P D=$ Continuing Professional Development $; C E=$ Continuing Education

If yes, how many hours annually?

\begin{tabular}{|l|c|c|}
\hline & Yes & No \\
\hline Is any funding available to trainees for attendance at meetings or courses? & & \\
\hline Do trainees rotate to other units locally, nationally, overseas? & & \\
\hline Is passing an annual or continual assessment a requirement to continue? & & \\
\hline Is remedial training available for trainees who are failing? & & \\
\hline
\end{tabular}

Briefly comment on how in-training assessments are managed. 
Briefly comment on the format of College/School or other formal final examinations (eg written papers, practical and oral).

Is there any veto procedure for candidates who fail a part of the exam

\begin{tabular}{|l|l|}
\hline Yes & No \\
\hline &
\end{tabular}

If yes, describe the procedure

How is training programme quality assured?

\section{Section 4 - Facilities and Resources}

Select/highlight this tick symbol $\checkmark$ then copy and paste into yes, no or blank boxes (or use $\boldsymbol{x}$ )

\begin{tabular}{|l|c|c|}
\hline & Yes & No \\
\hline Do trainees have dedicated office space? & & \\
\hline Do trainees have access to a dedicated personal computer? & & \\
\hline Do trainees have access to the internet? & & \\
\hline Are trainees required to have a personal development plan? & & \\
\hline Is the training program managed by a dedicated program director? & & \\
\hline Does the trainee have an educational supervisor? & & \\
\hline Is training provided to the trainers on teaching and assessment? & & \\
\hline
\end{tabular}

What is average number of trainers (consultants) per trainee

\begin{tabular}{|l|l|l|l|l|l|l|l|l|l|}
\hline 1 & 2 & & 3 & & 4 & & 5 & & 6 or more \\
\hline
\end{tabular}

Is formal appraisal carried out on a regular basis?

Yes

If yes how frequently?

\begin{tabular}{|l|l|l|}
\hline & Yes & No \\
\hline Are trainees paid a salary/stipend whilst training? & & \\
\hline If yes, what is the annual salary/stipend converted to US dollars? & $\$$ & \\
\hline
\end{tabular}

